\title{
Muscle Weakness
}

National Cancer Institute

\section{Source}

National Cancer Institute. Muscle Weakness. NCI Thesaurus. Code C50658.

A reduction in the streng th of one or more muscles. 